\title{
Surgery in the treatment of locally advanced lung carcinoma
}

\author{
R. A B B E Y SMITH \\ From the Thoracic Surgical Unit, King Edward VII Memorial Chest Hospital, \\ Hertford Hill, Warwick
}

Many differing views exist on the management of locally advanced lung carcinoma. One reason for this is that experience has shown that the most reliable method of determining the extent of the spread outside the lung is by thoracotomy. Having confirmed the extent of invasion by exploration, opinions vary on the subsequent steps in management, from immediate closure of the chest followed by radiation therapy to an attempt at resection in every instance, despite invasion of mediastinal structures. We have followed this latter course, even though we are aware of the advantages of other methods and of the very small return from this form of surgery. In so doing, we emphatically do not advocate a policy of operating on clearly inoperable lesions, using this term in the strictest surgical sense, and, in fact, our high resectability rate suggests that for various reasons many patients are rejected who would be operated upon in surgical centres averaging a more usual resectability rate of about $75 \%$ of patients explored.

In this contribution I will describe the fate of patients from whom portions of lung carcinoma in inaccessible mediastinal structures could not be removed at the time of resection, suggest indications for resection of this nature, and consider from a small experience the possible benefits from surgery in three conditions arising from extension of tumour beyond the confines of the lung, namely, superior vena caval obstruction, the superior sulcus syndrome, and oesophagobronchial fistula due to penetration of the oesophagus by lung carcinoma.

The statistics of this study may be summarized in this way. Of 510 patients, the tumour was removed by some form of resection in 489 , and in 21 resection was not possible. The resectability rate is 95.9 per cent. Of the 489 patients whose tumour was resected, 33 died in hospital following operation, an operative mortality of 6.6 per cent. Every patient was operated upon and followed up personally. In the ten-year period under review it is estimated that 4,000 patients were referred for a surgical opinion, although many were clearly inoperable cases. Thus, only one in every eight patients seen was operated upon.

From an area in the county of Warwickshire in which the total deaths from lung carcinoma and the number of patients operated upon can be estimated, it is believed that $\mathbf{3 5 0}$ died from lung carcinoma and that 27 patients were explored during the same period from the same area. It appears, therefore, that only one in every 13 cases of lung carcinoma is operable. These 510 patients are a selected group.

Concurrently with the practice of resecting locally advanced lung tumours, a number of local excisions and segmental resections have been carried out with satisfactory long-term results. There are strong reasons for treating the individual patient rather than the disease, and, from a consideration of the results, for making definite indications for resection even when total removal of the tumour is not possible. Judged by the extent of its invasion of mediastinal structures, the differences between the tumour which is totally resectable, the tumour which is incompletely resectable, and that which is not considered resectable, may be small. For this reason, in forming indications for partial resection of an advanced tumour, factors other than the extent of mediastinal invasion influence the decision to continue with resection.

As suggested by Chamberlain, McNeill, Parnassa, and Edsall (1959), the operation under discussion will be described as a non-curative resection inasmuch as tumour removal is incomplete. They define this operation and promote its use in certain circumstances. It is clear that the higher the resectability rate which is achieved, the greater must be the incidence of resections in which tumour removal is incomplete. Reviewing his experience of both conservative and extensive 
resection for carcinoma, Price Thomas (1959) writes 'there is every justification for extending our indications for surgery to include such extensions of the disease that are within the competence of removal, for none can judge at the time of operation which patient will or will not have a long term survival apparently free from disease.'

The techniques for excision of adjacent mediastinal structures are described. Chamberlain et al. (1959) have summarized reasons for a guardedly aggressive attitude to lung carcinoma and described their experience. No attempt will be made to add to the abundant evidence, succintly presented in the papers quoted, of the advantages of an extensive operation which removes the macroscopic tumour in its entirety. In attempting such an operation, total removal of the entire tumour was found to be impossible on 65 occasions in this series, and in each of these 65 patients definite tumour tissue remained in an inaccessible mediastinal structure after removal of the lung containing the main tumour. The early results of this procedure and tentative reasons for resection, rather than regarding the lesion as irresectable, have been published (Abbey Smith, 1957).

The value of any operation for lung carcinoma may in part be assessed by its effect on the natural history of the tumour. The choice of the particular operative method is dependent almost entirely on the surgeon's experience of the results of the operation. This empirical method of choice and the variations in the natural history of every tumour tend to make any assessment of an operation an unrewarding task. Convincing arguments against the value of the operation described in this paper, based on the slow rate of growth of some tumours, the high operative mortality, and the availability of other more satisfactory methods, have not altered our view that once the patient's treatment has reached the stage of thoracotomy, incomplete removal of the tumour is a satisfactory method in the circumstances described under 'Indications for Operation', provided, of course, that an attempt at complete removal has failed.

Before considering the indications for operation, it should be stated that extensive resection, where removal is complete, and the results of pneumonectomy for carcinoma involving only the lung will not be discussed.

\section{INDICATIONS FOR OPERATION}

It is necessary to describe briefly the indications for operation in the cases in this series before considering reasons for resecting a lesion which apparently offers no hope of cure because tumour removal is incomplete.

No patient with recognizable metastases has $\frac{\bar{D}}{\vec{D}}$ been operated upon. Prolonged palpation of both $\varrho$ supraclavicular regions for glandular involvement is is necessary, in particular deep behind the clavicle $\vec{\circ}$ since this is the commonest, and in our experience the most frequently overlooked, site for the detec- $\vec{\omega}$ tion of glandular metastasis. It may require some time to examine the area thoroughly, and not $\underset{x}{x}$ infrequently a second examination has been $\vec{\infty}$ thought necessary to confirm the presence of small $\rightarrow$ involved glands. Palpation of the skin of the whole area of the chest, abdomen, and back with the flat $\mathrm{O}$ of the hand occasionally reveals an undetected skin nodule, of which the patient is unaware. Patients with recent paralysis of the diaphragm or recurrent laryngeal nerve palsy have been rejected, but pleural effusion is not an absolute contraindication. Symptoms due to superior vena caval obstruction, tumours of the superior sulcus, and tumours involving the oesophagus form a group which will be discussed in more detail.

The indications for exploration may be regarded as conforming to standard practice except for this special group.

The local extent of the tumour is estimated by a full clinical examination, examination of the patient's radiographs, and bronchoscopy. Generally no other ancillary method of confirming that resection is feasible has been used. Where the diagnosis is obscure, all available methods have been utilized. On only a few occasions has this simple method of assessment failed to give accurate data on the local extent of the tumour. It may mislead when a left upper lobe tumour involves the left pulmonary artery, or a tumour at basal segmental level in the lower lobe penetrates the atrium further than expected; a suspicion of these possibilities may be found by a close study of the radiographs.

When the necessity for an extensive operation seems likely the patient is kept in hospital under observation for a long pre-operative period in most instances. Provided that the patient is encouraged by those with whom he comes into contact to use this period in improving his state of fitness for such an operation, it is always to his advantage. Equally so is the acquisition of more insight by the patient into the reasons for physiotherapy, breathing exercises, and other forms of discipline at first quite meaningless to him. We have also found it of value to accustom the patient to the feel of the Smith-Clarke positive pressure respirator at the estimated setting of the respirator 
for several periods each day over many days before operation, using the best-fitting face attachment. Thoroughly accustoming everyone concerned in the use of the respirator has reduced the number of post-operative tracheotomies and assisted in maintaining lung expansion. Respiratory function tests, including the shortest time taken to walk a mile, and the physical state at the conclusion of this test, have been used as evidence of the patient's ability to withstand a severe operation, and also to form an estimate of the amount of lung removal which the patient will tolerate.

In some patients a general lack of good health is evident, although the tumour appears to be of small dimensions. At one time we believed that a patient sufficiently incapacitated to require admission to hospital because of symptoms due to the presence of the tumour was unlikely to be cured by operation. This generalization is obviously false. A patient in poor health with perhaps a prolonged period of loss of weight appears, however, to be less likely to be cured by operation than does the patient with a similar tumour whose general condition is unaffected. This may indicate overt metastases, the circulation of tumour cells in the blood, or a truly multicentric tumour, if such exists.

If an estimate of the possibility of early metastases is made before the patient is explored, it is frequently in the group in poor health in whom early post-operative metastases become manifest without there being any figure or finding, other than experience, to support the likelihood of metastases occurring soon after operation. This indefinable consideration in the pre-operative assessment is another example of the empirical method of selection for operation in use. Conversely, normal good health, except for the presence of the tumour, is always an encouragement to explore, and, if total removal is not possible, to carry out as complete a removal as possible. In reaching the decision to explore, we have not been much influenced by the consideration that operation allows the patient to feel that a curative treatment is being offered or, more simply, that something is being done. Where this is the only indication pointing to operation, the patient must be convinced that radiotherapy is the correct treatment, if any doubt exists in his mind. If put with sufficient conviction, this has the effect, as far as can be told, of satisfying the patient.

The decision for or against exploration is made in every patient on these criteria. When at operation the tumour is found to be sufficiently advanced to be irremovable in its entirety, the choice lies between closure without resection or a non-curative resection with inaccessible tumour remaining in the mediastinum. The irresectability of the tumour in some instances may only be confirmed by prolonged dissection, and it is at times possible to achieve total removal which at first sight seemed impossible.

A non-curative resection is considered to be indicated in the following circumstances: when the patient is young and able to withstand a severe operation; if the atrium or the pulmonary artery appear to be the only sites of residual tumour, and especially if the growth itself feels hard and fibrous and not obviously invading lymphatic glands. A number of oat-cell tumours may at operation show these characteristics and, although it is customary to accept that the oat-cell tumour has a bad prognosis, our results do not always confirm this, particularly when the growth seems only locally invasive, judged by its characteristics on palpation and the absence of penetration except into the atrium or pulmonary artery. Not only is the behaviour of the residual portion of an oatcell tumour unpredictable, but also there may be a variation between the histology of the biopsy specimen and that of the main intrapulmonary tumour. The results of treatment may illustrate these points. There may, of course, be a variety of forms of extension to the mediastinum. Extensive glandular involvement may be associated with involvement of the atrial wall, for instance, and in these circumstances the indications become less clear and the prognosis less favourable, but resection is carried out when possible, reducing the residual tumour to its smallest possible dimensions. We have not continued with resection in the presence of soft encephaloid lymph glands beyond the range of block dissection, where tumour would remain in bone such as the vertebral bodies, or when the patient was considered fit only for a lobectomy and the local extent required pneumonectomy. In each of these circumstances the operation has been concluded and an alternative form of treatment undertaken. The reasons for abandoning operation are shown in Table II.

\section{RESULTS OF NON-CURATIVE RESECTION}

In the paper previously quoted, the results of resection when the residual tumour could not be removed were presented (Abbey Smith, 1957). A worth-while result from this procedure was regarded as one in which the patient survived at least eight months and was able to resume work. Exactly half of the survivors of non-curative resection fulfilled these criteria. This trend has 
TABLE I

PATIENTS SURVIVING MORE THAN TWO YEARS AFTER NON-CURATIVE RESECTION

\begin{tabular}{|c|c|c|c|c|c|c|}
\hline Patient & Age & $\begin{array}{l}\text { Type of } \\
\text { Cell }\end{array}$ & $\begin{array}{l}\text { Site of } \\
\text { Residual Carcinoma }\end{array}$ & $\begin{array}{l}\text { Alive or } \\
\text { Dead }\end{array}$ & $\begin{array}{l}\text { Time since } \\
\text { Operation } \\
\text { (Months) }\end{array}$ & $\begin{array}{l}\text { Clinical Evidence } \\
\text { of Extension of Growth }\end{array}$ \\
\hline $\begin{array}{l}\text { L.J. } \\
\text { H.H. } \\
\text { A.D. } \\
\text { A.A. } \\
\text { F.I. } \\
\text { T.W. } \\
\text { W.B. } \\
\text { J.B. }\end{array}$ & $\begin{array}{l}48 \\
55 \\
44 \\
53 \\
51 \\
43 \\
59 \\
55\end{array}$ & $\begin{array}{l}\text { Adenocarcinoma } \\
\text { Oat } \\
\text { Adenocarcinoma } \\
\text { Oat } \\
\text { Squamous } \\
\text { Adenocarcinoma } \\
\text { Squamous } \\
\text { Squamous }\end{array}$ & $\begin{array}{l}\text { Left pulmonary artery } \\
\text { Atrial wall } \\
\text { Atrial wall } \\
\text { Atrial wall } \\
\text { Mediastinal glands } \\
\text { Atrial wall } \\
\text { Left pulmonary artery } \\
\text { Bronchus }\end{array}$ & $\begin{array}{l}\text { Alive } \\
\text { Alive } \\
\text { Alive } \\
\text { Alive } \\
\text { Alive } \\
\text { Alive } \\
\text { Alive } \\
\text { Dead }\end{array}$ & $\begin{array}{l}98 \\
92 \\
83 \\
69 \\
33 \\
32 \\
24 \\
84\end{array}$ & $\begin{array}{l}\text { None } \\
\text { None } \\
\text { None } \\
\text { None } \\
\text { None } \\
\text { None } \\
\text { None } \\
\text { Haemoptysis with normal radiograph, }\end{array}$ \\
\hline $\begin{array}{l}\text { H.G. } \\
\text { W.H. } \\
\text { P.M. } \\
\text { J.R. }\end{array}$ & $\begin{array}{l}48 \\
54 \\
42 \\
60\end{array}$ & $\begin{array}{l}\text { Squamous } \\
\text { Oat } \\
\text { Oat } \\
\text { Oat }\end{array}$ & $\begin{array}{l}\text { Mediastinal glands } \\
\text { Left pulmonary artery } \\
\text { Mediastinal glands } \\
\text { Left pulmonary artery }\end{array}$ & $\begin{array}{l}\text { Dead } \\
\text { Dead } \\
\text { Dead } \\
\text { Dead }\end{array}$ & $\begin{array}{l}49 \\
36 \\
28 \\
25\end{array}$ & $\begin{array}{l}\text { Cervical glands and secondaries in rib } \\
\text { Dysphagia from mediastinal glands } \\
\text { Cervical glands and enlarged liver } \\
\text { Cervical glands }\end{array}$ \\
\hline
\end{tabular}

continued; the longer term results of those surviving two years or more are presented in Table I. These patients are the survivors from a total of 65 non-curative resections.

Although, by comparing the results shown in Table I with those of closure of the chest shown in Table II, similar tumours are not being compared, there is a striking difference in the outcome of the two procedures. Of particular interest are the four patients surviving in normal health with tumour tissue on the wall of the atrium (Table I). These patients have been seen at regular intervals since operation and no evidence of extension of the disease exists. Two had an oat-cell carcinoma of the lung. The existence of a considerable tumour remnant in each patient at the conclusion of the resection was indisputable and confirmed by a biopsy, which is carried out routinely if doubt exists. An explanation of the survival of these patients is not easy. There was no pre-operative evidence that the tumour was of abnormally slow growth habit, all the patients had symptoms, and none of the tumours was detected by routine mass radiography. The wall of the atrium may be an unfavourable medium for tumour growth. Price Thomas (1959) has pointed out that the pericardium may act as a barrier to extension of growth. The pulmonary artery, in our experience, may be invested with a collar of growth and its wall remain free of invasion. It is possible that for biochemical reasons these three tissues, the pericardium, the pulmonary artery, and the atrium, do not support tumour growth. The absence of free lymphatic drainage of the atrial wall may also have an effect in retarding extension, or the metabolism of the residual portion of tumour may be so altered that it becomes symbiotic and ceases to behave as an invasive neoplasm. The behaviour of tumour remaining in the atrial wall may be compared with its progress when left in the chest wall. In six patients tumour has remained in the chest wall when excision of the chest wall has not been practicable, and reference to Table I will show that none of these patients has survived two years. Growth of the tumour has progressed locally in each patient. This contrast is a reason for believing that some difference exists between the chest wall and the atrium as media for propagation of tumour in natural conditions. The reason for this difference may give a clue to a method of reducing the vitality of pulmonary cancer. We think some biochemical factor is involved.

As a means of treating the patient, non-curative resection where residual tumour is confined to the atrium seems a thoroughly acceptable and worthwhile method. This applies also to residual growth on the stump of the pulmonary artery. The importance of the macroscopic appearance and feel of the tumour has been mentioned. This has governed the decision whether to continue with a non-curative resection to a greater extent than has the histopathology of the tumour obtained from bronchial biopsy. Patient A.A. (Table I) had an oat-cell tumour, confirmed by bronchial biopsy. A considerable portion of tumour could not be resected from the atrial wall. The operation note states that 'the tumour appears to be locally invasive and, in spite of the tumour on the atrial wall, a worthwhile result may be obtained from this $N$ palliative resection'. The patient is alive and working nearly six years after resection. The possibility of a favourable outcome was considered solely on $\mathrm{C}$ the local appearance of the tumour.

For the patient with a large number of soft 0 encephaloid glands in the mediastinum it would $\varnothing$ appear that surgery is of little value, although the $\stackrel{\mathcal{P}}{\rightarrow}$ final method of confirming the existence of glands 0 of this character can only be by exploration of the lesion. The results of thoracotomy without $\stackrel{\mathbb{Q}}{\stackrel{Q}{Q}}$ removal of the tumour, the length of survival, and $\stackrel{\mathbb{Q}}{\Omega}$ the reasons for not removing the tumour are shown in Table II. 
TABLE II

ANALYSIS OF PATIENTS IN WHOM RESECTION WAS IMPOSSIBLE OR POSSIBLE BUT NOT INDICATED

\begin{tabular}{|c|c|c|c|c|c|}
\hline Patient & Age & Site & Type of Cell & Reason for Abandoning Resection & $\begin{array}{l}\text { urvival } \\
\text { Conths) }\end{array}$ \\
\hline $\begin{array}{l}\text { P.D. } \\
\text { C.W. } \\
\text { A.S. } \\
\text { H.P. } \\
\text { J.M. } \\
\text { J.L. }\end{array}$ & $\begin{array}{l}46 \\
43 \\
58 \\
52 \\
62 \\
55\end{array}$ & $\begin{array}{l}\text { L.M.L } \\
\text { L.U.L. } \\
\text { L.U.L. } \\
\text { R.L.L. } \\
\text { L.L.L. } \\
\text { L.U.L. }\end{array}$ & $\begin{array}{l}\text { Oat } \\
\text { Unknown' } \\
\text { Unknown } \\
\text { Oat } \\
\text { Squamous } \\
\text { Oat }\end{array}$ & $\begin{array}{l}\text { Involvement of pulmonary artery, obliteration of pericardium } \\
\text { Involvement of pulmonary artery, multiple glands } \\
\text { Gland mass filling concavity of aortic arch } \\
\text { Long segment of oesophagus involved } \\
\text { Involvement of pulmonary artery } \\
\text { Involvement of pulmonary artery, multiple glands, and } \\
\text { atrial fibrillation }\end{array}$ & $\begin{array}{l}3 \\
5 \\
\text { H.D. } \\
3 \\
7 \\
7\end{array}$ \\
\hline $\begin{array}{l}\text { F.L. } \\
\text { P.B. } \\
\text { A.C. } \\
\text { H.G. } \\
\text { D.E. } \\
\text { A.K. } \\
\text { G.T. } \\
\text { A.W. } \\
\text { J.W. } \\
\text { F.C. } \\
\text { R.C. } \\
\text { B.W. } \\
\text { W.S. } \\
\text { F.S. } \\
\text { E.W. }\end{array}$ & $\begin{array}{l}57 \\
45 \\
56 \\
46 \\
56 \\
38 \\
52 \\
54 \\
60 \\
60 \\
69 \\
67 \\
49 \\
55 \\
44\end{array}$ & $\begin{array}{l}\text { L.M.L. } \\
\text { L.M.L. } \\
\text { L.L.L.. } \\
\text { R.L.L. } \\
\text { L.U.L. } \\
\text { R.L.L. } \\
\text { R.M.L. } \\
\text { L.M.L } \\
\text { L.U.L. } \\
\text { L.U.L. } \\
\text { R.U.L. } \\
\text { R.M.L. } \\
\text { L.M.L. } \\
\text { L.U.L. } \\
\text { R.L.L. }\end{array}$ & $\begin{array}{l}\text { Unknown } 1 \\
\text { Squamous } \\
\text { Oat } \\
\text { Squamous } \\
\text { Adenocarcinoma } \\
\text { Unknown'1 } \\
\text { Squamous } \\
\text { Oat } \\
\text { Unknown } 1 \\
\text { Unknown 1 } \\
\text { Unknown } 1 \\
\text { Oat } \\
\text { Oat } \\
\text { Adenocarcinoma } \\
\text { Oat }\end{array}$ & $\begin{array}{l}\text { Involvement of pulmonary artery } \\
\text { Long segment of oesophagus involved } \\
\text { Involvement of aortic arch } \\
\text { Widespread involvement of mediastinum } \\
\text { Involvement of pulmonary artery } \\
\text { Widespread glands and tumour within atrium } \\
\text { Long segment of oesophagus involved } \\
\text { Lobectomy not possible, pneumonectomy not indicated } \\
\text { Lobectomy not possible, pneumonectomy not indicated } \\
\text { Lobectomy not possible, pneumonectomy not indicated } \\
\text { Lobectomy not possible, pneumonectomy not indicated } \\
\text { Inaccessible glands, pneumonectomy technically possible } \\
\text { Inaccessible glands, pneumonectomy technically possible } \\
\text { Inaccessible glands, pneumonectomy technically possible } \\
\text { Inaccessible glands, pneumonectomy technically possible }\end{array}$ & $\begin{array}{r}12 \\
2 \\
1 \\
1 \\
3 \\
1 \\
4 \\
3 \\
2 \\
3 \\
3 \\
3 \\
2 \\
12 \\
46\end{array}$ \\
\hline
\end{tabular}

${ }^{1}$ No biopsy available at bronchoscopy or thoracotomy. $\quad{ }^{2}$ Hospital death

In a number of patients resection, though technically possible, was not carried out either because of extensive glandular involvement or because pneumonectomy was not thought advisable in a patient who was considered fit only for lobectomy. Patient E.W. (Table II) illustrates some of the difficulties involved in deciding on prognosis and the variability in the histopathology of the tumour. The patient had an endobronchial tumour filling the right lower lobe bronchus, which at bronchoscopy resembled a bronchial adenoma. The biopsy showed an oat-cell tumour. At operation pneumonectomy, though possible, was not performed because of the extent of glandular involvement in the pulmonary ligament, across the mid-line, and above the azygos arch. A gland removed from the upper mediastinum showed invasion by squamous carcinoma. The patient was started on radiotherapy, which was abandoned before half the proposed course had been completed because of a severe skin reaction. $\mathrm{He}$ returned to his previous manual labour and lived in good health for 46 months from the time of exploration. At death the only evidence of extension of the tumour was a palpable malignant mass in the abdomen.

The $6.6 \%$ mortality from operation is not excessive. It includes all resections of all types, including lobectomy. The most probable reason for a reduction in the operative mortality during the last five years of the period is that younger patients have been operated upon. Contrary to what was expected before analysis of the figures, the average age of patients who had worth-while results from non-curative resection (Table I), of patients who had a thoracotomy only (Table II), and of patients who died post-operatively is almost identical at about 54 years of age in each group.

\section{SUPERIOR VENA CAVAL OBSTRUCTION}

Involvement of this structure may be the only hindrance to a satisfactory operation (Price Thomas, 1959). Not infrequently the patient is young and the tumour is confined locally to the region anterior to the right upper lobe bronchus. The extent of caval involvement may be such that any form of piecemeal removal of tumour off the vessel is impossible. Whether operation should ever be advised for established vena caval obstruction is equivocal. In a young patient with good respiratory function, in whom evidence of slow growth exists, exploration with resection of the cava and replacement by a Teflon graft is one form of treatment, which we have carried out in two patients.

Jarvis and Kanar (1954) successfully carried out pneumonectomy for lung carcinoma, with anastomosis of the cava to the atrium. The cava was clamped for an estimated time of 57 minutes, recovery from anaesthesia was normal, and the immediate post-operative course satisfactory. They state that two hours is the maximum period of time for which the cava may be occluded in the experimental animal without harmful after-effects. Ashburn, Sewell, and Huggins (1956) reported a patient alive and working seven months after pneumonectomy, caval excision, and replacement 


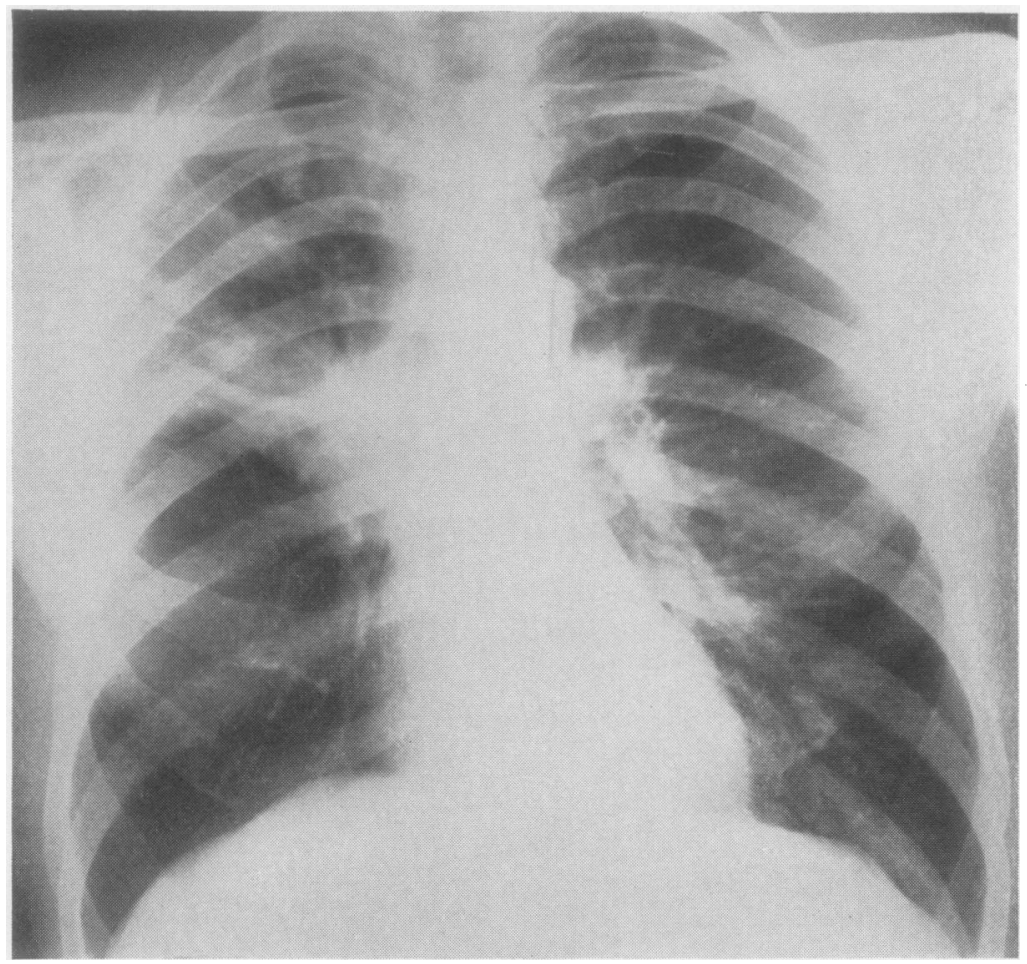

FIG. 1. Case 1. Chest radiograph immediately before operation.

by a freeze-dried aortic graft. Price Thomas (1959) described caval transection with anastomosis after pneumonectomy in two patients. Holman and Steinberg (1954) and Scannell and Shaw (1954) have discussed caval replacement. Botham, Dracopoulos, and Gale (1960) made a preliminary report on the use of a sponge Teflon prosthesis for superior vena caval replacement in dogs.

The advantages of pneumonectomy with resection of the vena cava over radiation therapy cannot be assessed. The problem is more than a simple choice between the two alternatives. Damage to the cava may make its replacement obligatory in a situation where a planned resection of the vessel was not proposed. The extent of caval involvement cannot always be accurately estimated by any method, and in some patients confirmation of the diagnosis of lung cancer may be impossible without operation. There would certainly appear to be a need for more caution in continuing with resection when there is caval involvement than when there is atrial involvement. The results of operation in some patients with atrial involvement are good, but in patients with caval involvement combined experience is too small and the late effects are unknown. The satisfactory results from radiation therapy in vena caval obstruction do not necessarily indicate, however, that resection has nothing to offer the patient. Flow through the prosthesis is more likely to be maintained when a pneumonectomy has been performed than when the prosthesis is inserted for non-malignant venous obstruction. The pneumonectomy space may be maintained at high negative pressures and the prosthesis is not subjected to the pressure effects of the expanded lung, both factors tending to improve flow through the reconstructed vein. In gross superior caval obstruction due to lung carcinoma it is unlikely that the azygos vein, an important collateral channel, will ever be preserved, but in ligation and division of the azygos all its branches should be preserved by division of the azygos as close to the vena cava as possible. The right superior intercostal vein represents an important collateral channel in $\stackrel{\mathcal{Q}}{+}$ superior vena caval obstruction. During operation 0 the patient is transfused through a leg vein, if $\bar{O}$ temporary occlusion of the vena cava is contemplated.

CASE 1 C. G., a man aged 51, complained of chest pain and haemoptysis of three months' duration. $\frac{0}{0}$ 
The chest radiograph is shown in Fig. 1. The right external jugular vein was prominent. Bronchoscopy showed a contracted right upper lobe orifice. No biopsy was possible. At operation a carcinoma was found obstructing the flow through the superior vena cava and obliterating the space between the superior pulmonary vein and the cava outside the pericardium. Apart from caval involvement the lesion was operable. The azygos vein was divided; the main bronchus was divided and sutured and the pericardium widely opened. The right pulmonary artery was ligated inside the pericardium. It was not possible to define a plane of separation between the pulmonary veins and the cava at its junction with the atrium. The vena cava was mobilized for $3 \mathrm{~cm}$. above the azygos branch and the patient over-inflated for several minutes. One clamp was placed across the vena cava at the upper limit of mobilization and another across both atria, including the cava and both pulmonary veins in the same clamp because of the difficulty of access. The lung and the cava were removed. The lower clamp was replaced by two separate clamps, one on the wall of the left atrium and the other on the right atrium. Both pulmonary veins were closed by suture and this clamp was removed. A $5.0 \mathrm{~cm}$. length of woven arterial graft of Teflon was used to bridge the gap between the vena cava and the right atrium. Direct resuture was not possible. Air was removed by release of the atrial clamp before completion of the suture. The cava was occluded for 20 minutes. The head of the table was raised as high as possible to assist venous drainage. A single dose of heparin was given. The flow through the prosthesis was satisfactory. The prosthesis and the sutured bronchial stump were

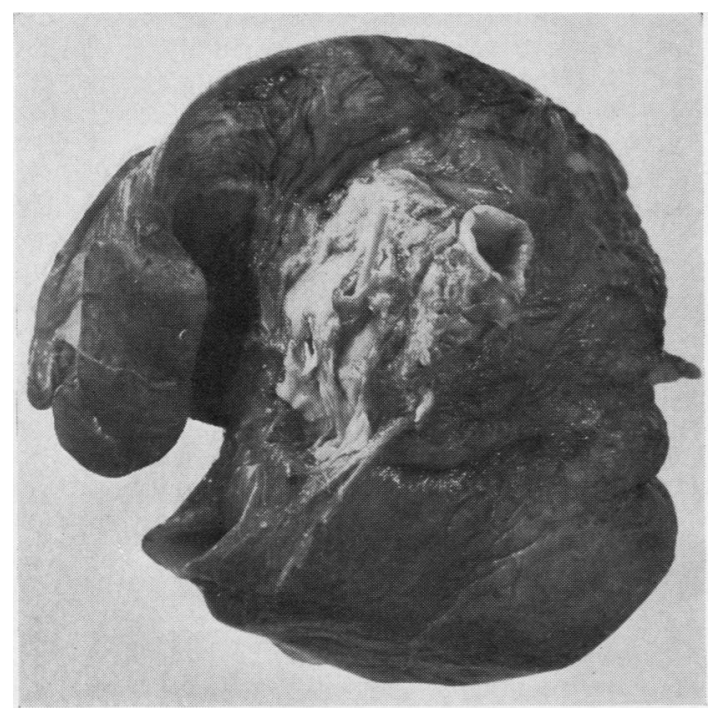

FIG. 2. Case 1. The pulmonary artery is probed. The cut end of the vena cava can be seen emerging from the tumour anterior to the artery.

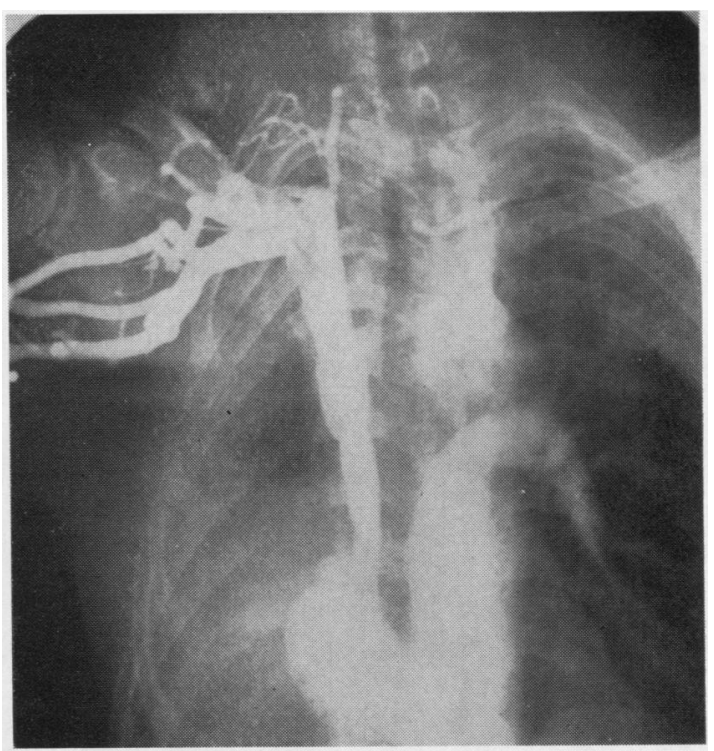

FIG. 3. Case 1. A two-second venous angiogram film showing free flow through the graft and the absence of collateral circulation. The position of the ligature on the right pulmonary artery can be seen.

separated as widely as possible and the chest was closed without drainage. The patient returned to consciousness at the completion of the operation. Haemorrhage into the pneumonectomy space was troublesome for the first 24 hours and was treated by aspiration and transfusion. The space was maintained at a more negative pressure than usual. The patient's convalescence was normal and he was up on the fourth day. Histology of the tumour showed a squamous carcinoma. The specimen is shown in Figure 2. Six months after operation the patient is following his previous occupation as vigorously as in the past. An angiogram taken six months after operation is shown in Figure 3.

CASE 2 A man, aged 48, was referred to hospital initially because of a cough. Although losing weight, he had recently noticed the need for a larger size in neck collars. There was engorgement of the neck veins. The radiograph of his chest at the time of operation is shown in Figure 4. The lateral view confirmed the proximity of the tumour to the vena cava. Bronchoscopy showed a carcinoma of the right upper lobe.

Because of the patient's age and the evidence of slow growth of the tumour judged by the chest radiographs over an interval of time, operation was advised.

At operation a large tumour mass surrounded the azygos vein and the portion of the superior vena cava immediately adjacent. No glands were palpable and the firm feel of the tumour suggested a relatively slow growth. After division of the azygos vein the main bronchus was divided at the carina. The pericardium 


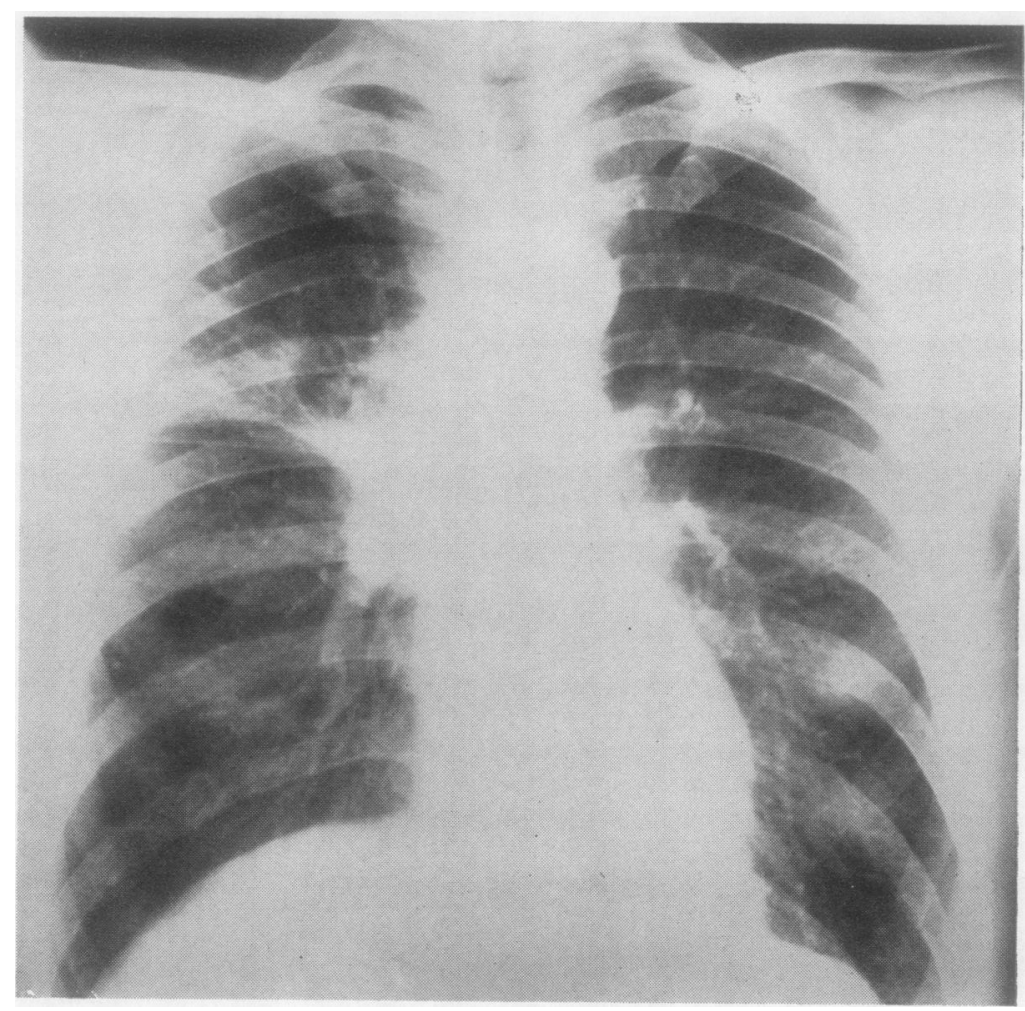

FIG. 4. Case 2. Chest radiograph immediately before operation.

was opened and both pulmonary veins clamped and sutured intrapericardially. The pulmonary artery was ligated within the pericardium but could not be divided safely because of the absence of length beyond the ligature. Using a technique similar to that in the previous case, the vena cava was clamped above the tumour and at a point $1.0 \mathrm{~cm}$. from its junction with the atrium. The pulmonary artery was then divided, freeing the lung. A $6.5 \mathrm{~cm}$. length of Teflon was sutured to both ends of the vena cava. The time of venous occlusion was 18 minutes. The patient returned to consciousness at the conclusion of the operation. Heparin was not used, but dindevan was given post-operatively.

For three days after operation the patient was cyanosed, especially over the lower part of the face and neck. There was marked venous engorgement of the neck and swelling of the right arm. Bleeding into the pneumonectomy space was not excessive. The evidence of venous obstruction subsided and at the time of the patient's discharge from hospital, four weeks after operation, the neck veins were not obvious although a fresh venous collateral channel appeared on the anterior chest wall. The tumour was a squamous cell carcinoma and is shown in Figure 5. Four months after operation the patient was free of symptoms, and, although the angiogram (Fig. 6) demonstrated complete occlusion of the prosthesis, no clinical evidence of superior vena caval obstruction could be detected. The absence of signs of caval obstruction is apparent in the photograph (Fig. 7) taken on the day after the angiogram.

It seems probable from a comparison of Figs. 6 and 7 that some factors other than occlusion of the vena cava contribute to the clinical picture of established caval obstruction in malignant disease, and that even if flow through the prosthesis is not maintained, it affords a satisfactory temporary channel during the development of an adequate yet clinically undetectable collateral venous system.

This patient died suddenly in a taxi-cab. At necropsy the cause of death was confirmed as pulmonary embolism from a venous thrombosis of the right leg. There was no recurrence of the carcinoma. A technical fault in the suturing of the prosthesis to the caval stump at the innominate end was the cause of the diminished flow and subsequent block.

\section{THE SUPERIOR SULCUS SYNDROME}

Contrary to current teaching, we believe that the superior pulmonary sulcus syndrome, characterized by pain in the arm, Horner's syndrome, destruction of bone, and atrophy of the hand 


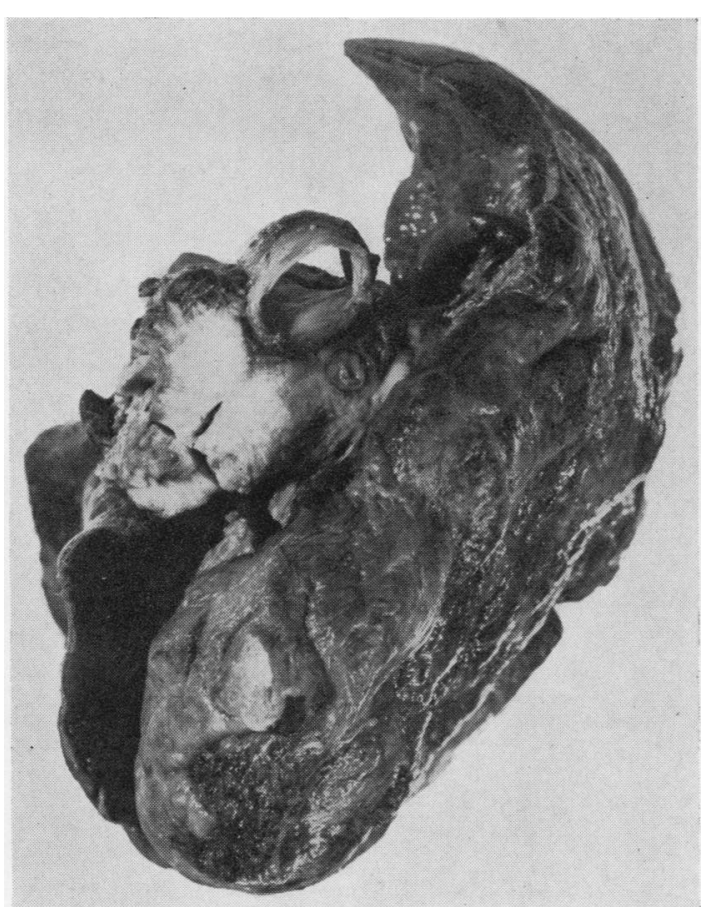

FIG. 5. Case 2. End-on view of the cut vena cava. The tumour surrounds half its circumference. The azygos vein is completely embedded in tumour. A portion of the tumour has been removed for biopsy.

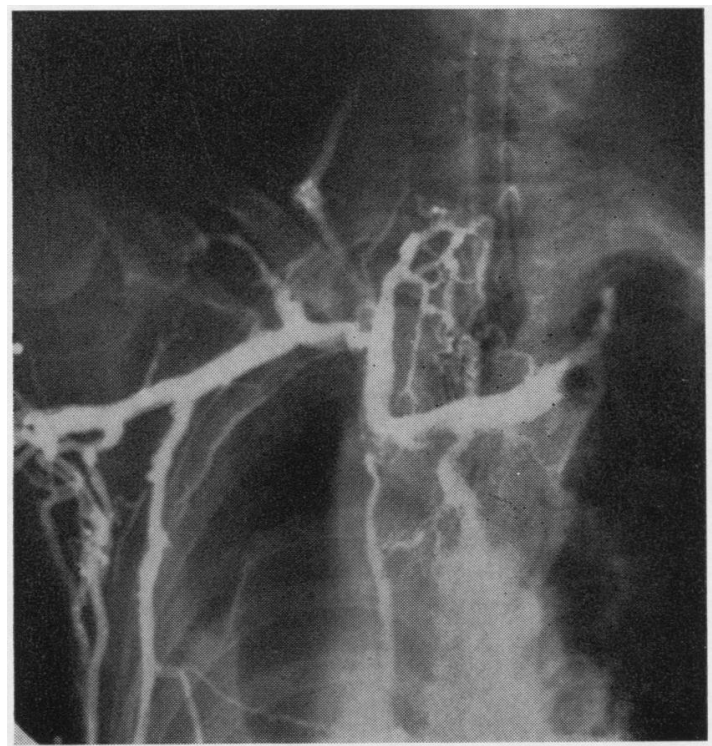

FIG. 6. Case 2. A two-second venous angiogram film demonstrating the block at the junction of the two innominate veins. The collateral circulation is predominantly through the branches of the axillary vein on the right side.

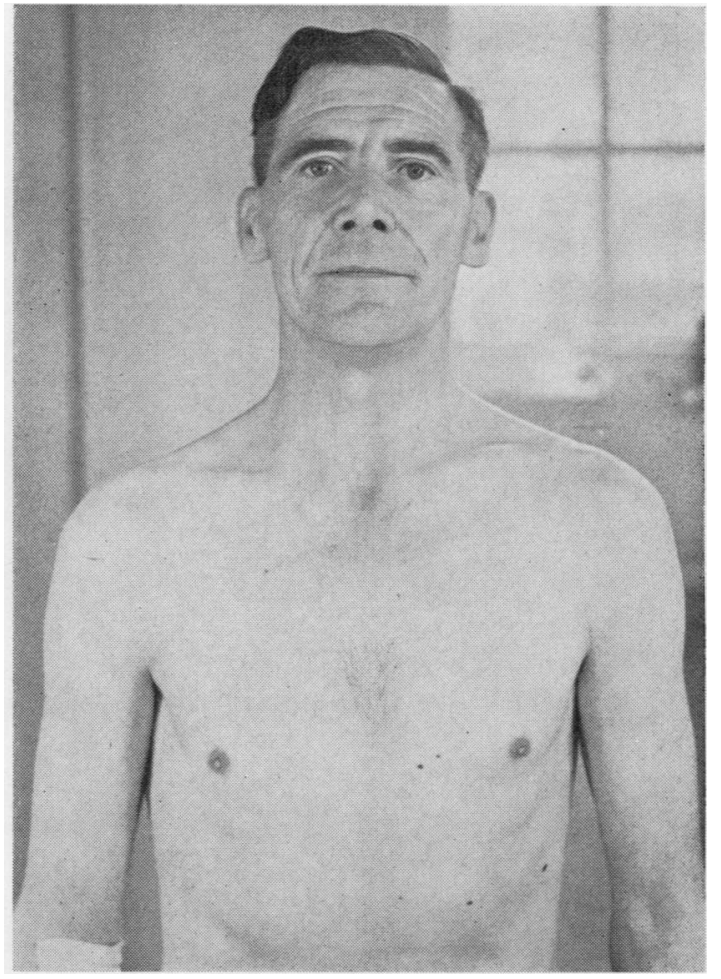

FIG. 7. Case 2. Photograph of patient taken on the day after the angiogram (Fig. 6) showing a normal appearance in spite of the complete block in the prosthesis.

muscles, may exceptionally be caused by a malignant tumour not of pulmonary origin, which, at the time of its description (Pancoast, $1924 ; 1932$ ), was known as the Pancoast tumour. Pancoast (1932) called this specific tumour a superior pulmonary sulcus tumour 'because this term implies its approximate location and a lack of origin from the lung, pleura, ribs, and mediastinum'. He also described (Pancoast, 1924) apical lung carcinoma, producing extreme pain in the arm when scarcely detectable radiographically, and later (Pancoast, 1932) described seven cases of the syndrome. No necropsies were possible on any of these cases and in only two were biopsies taken. He referred to the tumour in the same paper as a 'peculiar neoplastic entity found in the upper portion of the pulmonary sulcus of the thorax'. We think that a tumour of this description exists and that it is in no way associated with lung carcinoma, though at death it is indistinguishable from this disease. In its early manifestations the specific Pancoast tumour is more likely to be referred for treatment to the neurosurgeon. When the intra- 


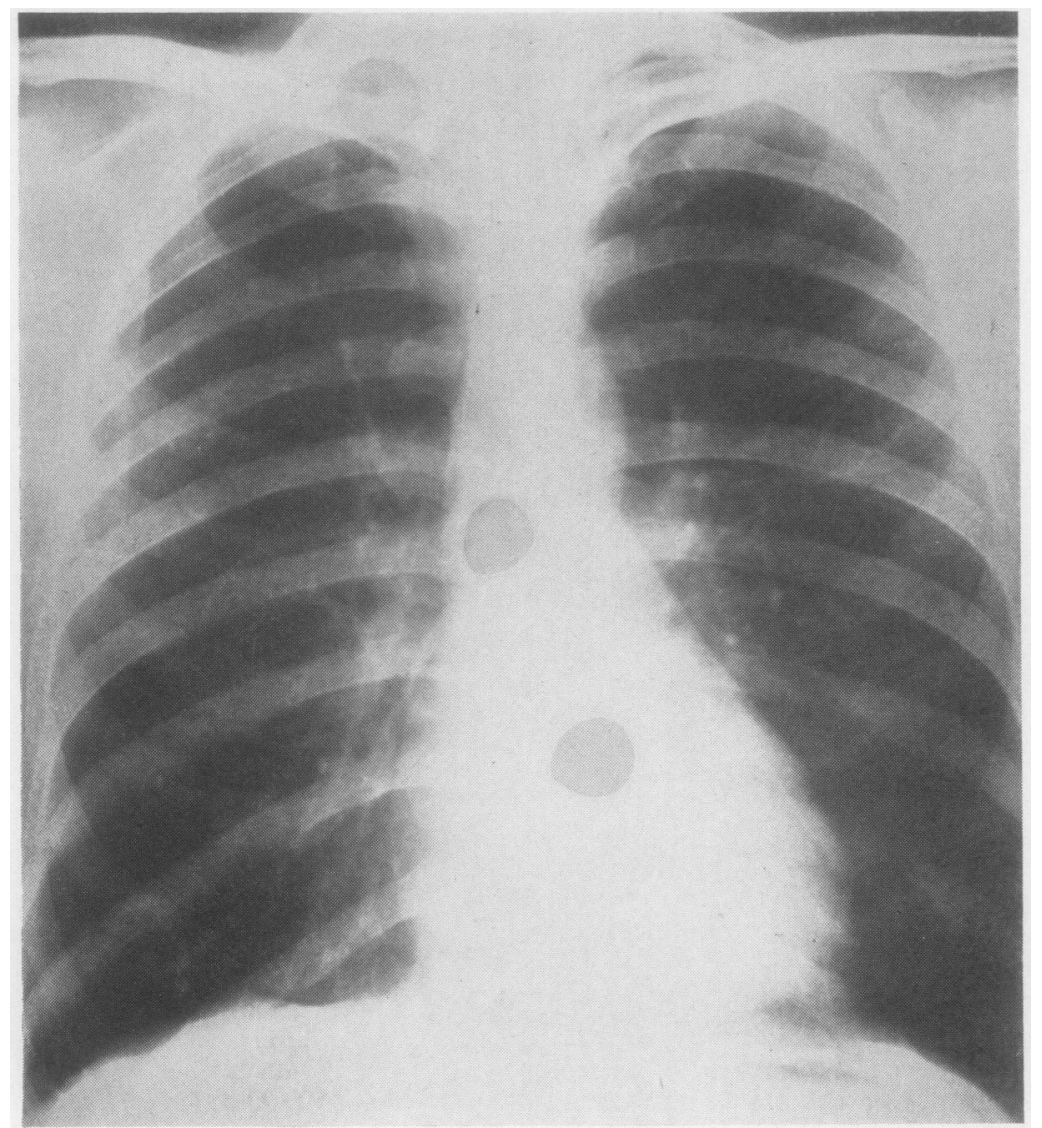

FIG. 8. Case 3. Chest radio. graph showing shadow at the right apex.

FIG. 9. Case 3. Film showing erosion of the posterior end of the second right rib.

Fig. 8

thoracic lesion is radiographically small in size, the possibility of the existence of such a tumour is a reason for exploration in a patient exhibiting the superior sulcus syndrome.

Eleven patients suffering from the superior sulcus syndrome have been explored, in each case because of the severity of the arm pain. In ten, a carcinoma at the apex of the lung was found, and in the remaining patient (case 3) a Pancoast tumour. This patient is described.

CASE 3 A man, aged 48, was referred in 1952 because of pain down the right arm and wasting of the small muscles of the right hand. A radiograph of the chest showed an ill-defined lesion at the right apex (Fig. 8). Tomograms confirmed destruction of the posterior end of the second right rib (Fig. 9). The patient had a Horner's syndrome. A diagnosis of carcinoma of the lung was made and operation advised.

At operation the lung was free and there were no adhesions to the apex of the pleura. Palpation of the right upper lobe revealed no tumour, and no glands

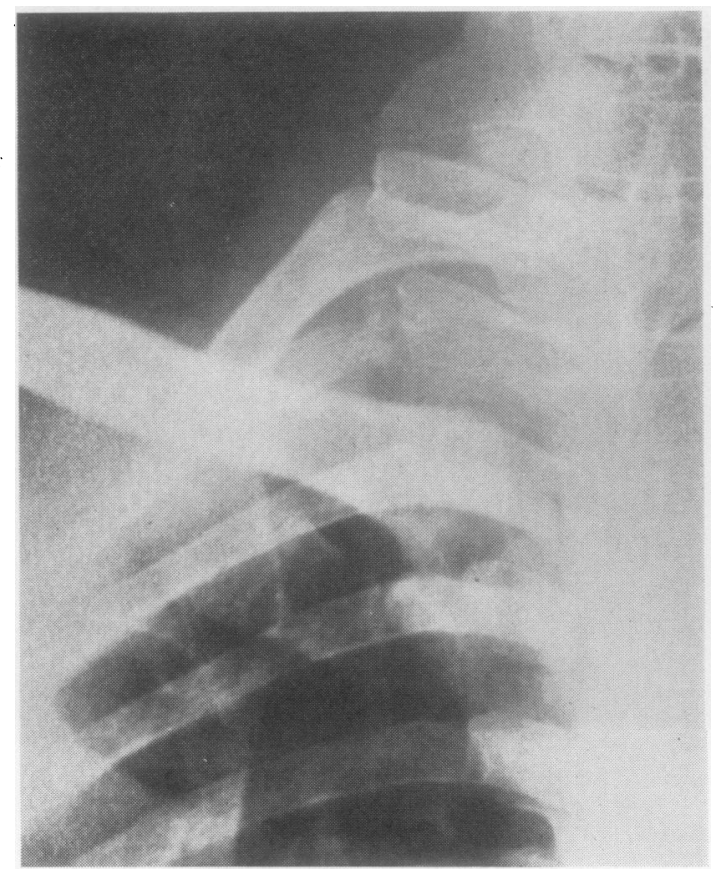




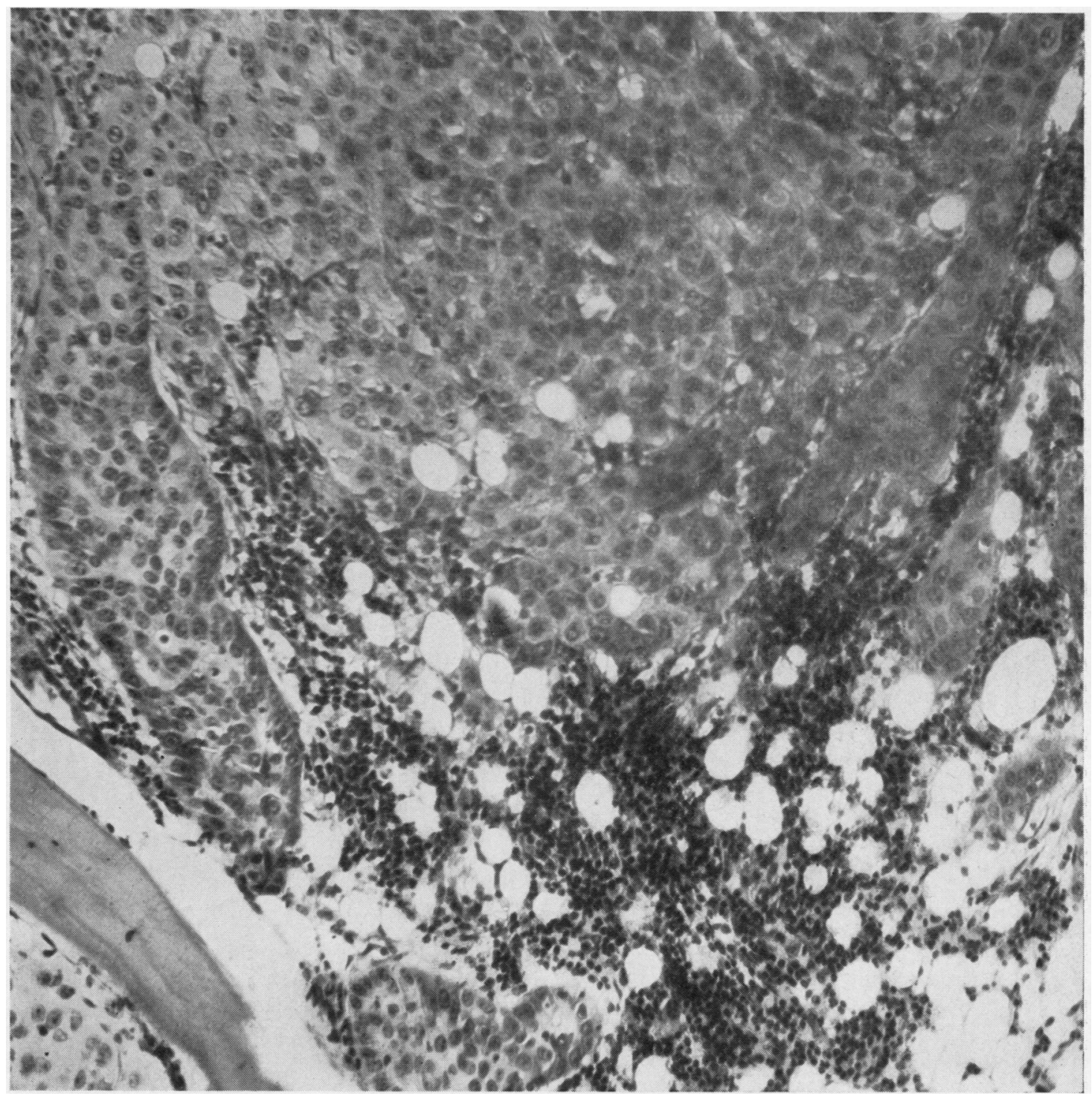

FIG. 10. Case 3. Photomicrograph of resected tumour.

were palpable at the hilum. Outside the parietal pleura a small white firm tumour lay in relation to the first thoracic root; it was somewhat flattened like a bean and about 2.5 by 1.5 by $1.5 \mathrm{~cm}$. in size. It was well circumscribed and wholly extrapleural. The tumour, the first nerve root, and the posterior ends of the upper three ribs were removed. Removal appeared complete. In an attempt to confirm that this tumour could have no possible relationship with an intrapulmonary tumour, the lung was inflated and, from the part where the lung touched the site of the tumour, a deep wedge biopsy was taken from the lung. This biopsy showed no evidence of carcinoma. The general structure of the resected tumour is shown in Figure 10. The patient was referred for radiation therapy and the pain disappeared. His radiograph 16 months after operation is shown in Figure 11. Nineteen months after operation the patient developed a paraplegia. from extension of the tumour to the spinal cord and he died. At necropsy the apex of the right lung, the pleura at the apex, and the adjacent structures were replaced by a sheet of tumour indistinguishable from an advanced lung carcinoma. The bodies of the first and second thoracic vertebrae were widely infiltrated. 


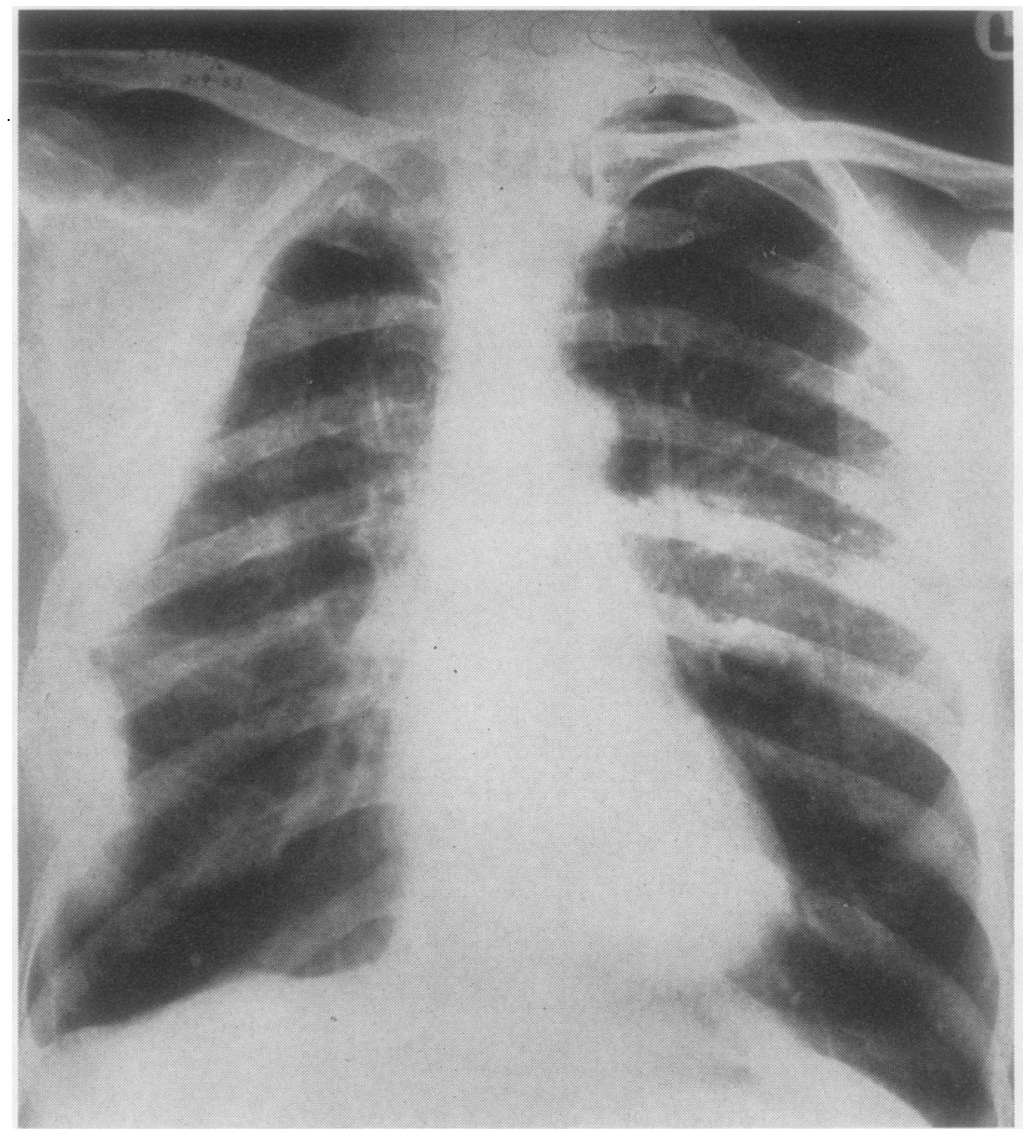

FIG. 11. Case 3. Chest radiograph 16 months after operation. The left mid-zone changes were thought to be due to radiotherapy.

No metastases or primary tumour elsewhere were present. Microscopically the tumour resembled the original in its appearance.

It would be difficult to offer a more precise definition of this tumour than a 'peculiar neoplastic entity'. Pancoast tumours, distinct from lung carcinoma, have been described by Clarke (1934), by Morris and Harken (1940), and by Herbut and Watson (1946), who consider they arise in bronchial rests, and by Fried (1948), who designates the lesion a sternoclavicular branchioma. James and Pagel (1944), though considering the tumour a specific entity, suggested that miniature scar carcinoma of the lung with involvement of the thoracic inlet is more descriptive of the pathology. This definition leaves unanswered the important question whether the adjacent lung should or should not be resected with the tumour. From the result of the findings in case 3 , the answer would appear to be in the negative when the superior sulcus syndrome is caused by the specific Pancoast tumour.

Persistent and progressive pain from extension $\frac{D}{0}$ of a lung tumour is a more common reason for surgical intervention than any doubt about the $N$ nature of the tumour. In the early stages of the $N$ development of the syndrome pain may be severe, $N$ although the general health is barely affected. It $\omega$ is at this stage that the use of opium derivatives in large doses to control pain seems distasteful. $\stackrel{\circ}{\subset}$ Good results have been obtained by wide resection $\mathscr{\mathbb { D }}$ of the involved upper lobe, the chest wall, and nerve roots. Chardack and MacCallum (1953, 1956) describe a patient in good health five years after operation. One patient (case 4) lived in com- $\frac{\rho}{8}$ fort for four years after resection of a lung tumour $\varnothing$ causing the syndrome. For five months before operation alternative methods were tried. The 


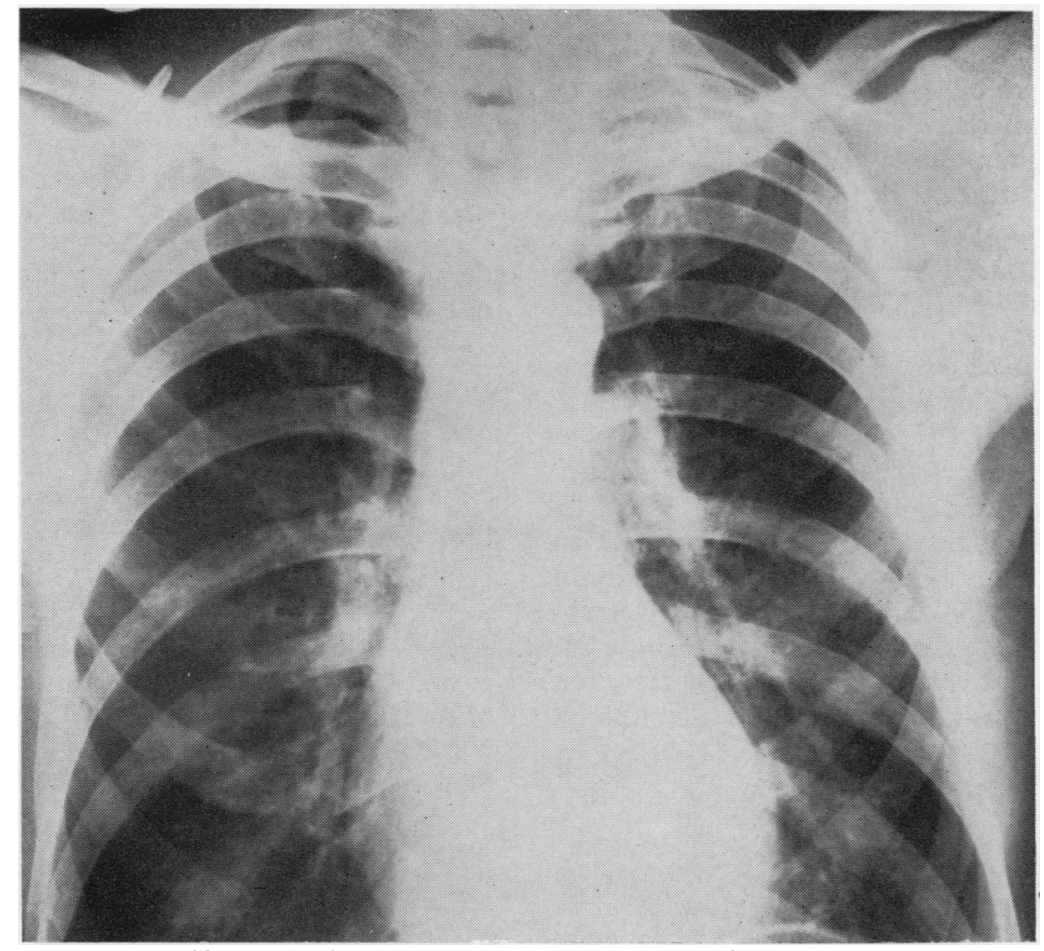

FIG. 12. Case 4. Chest radiograph showing left apiaal lesion.

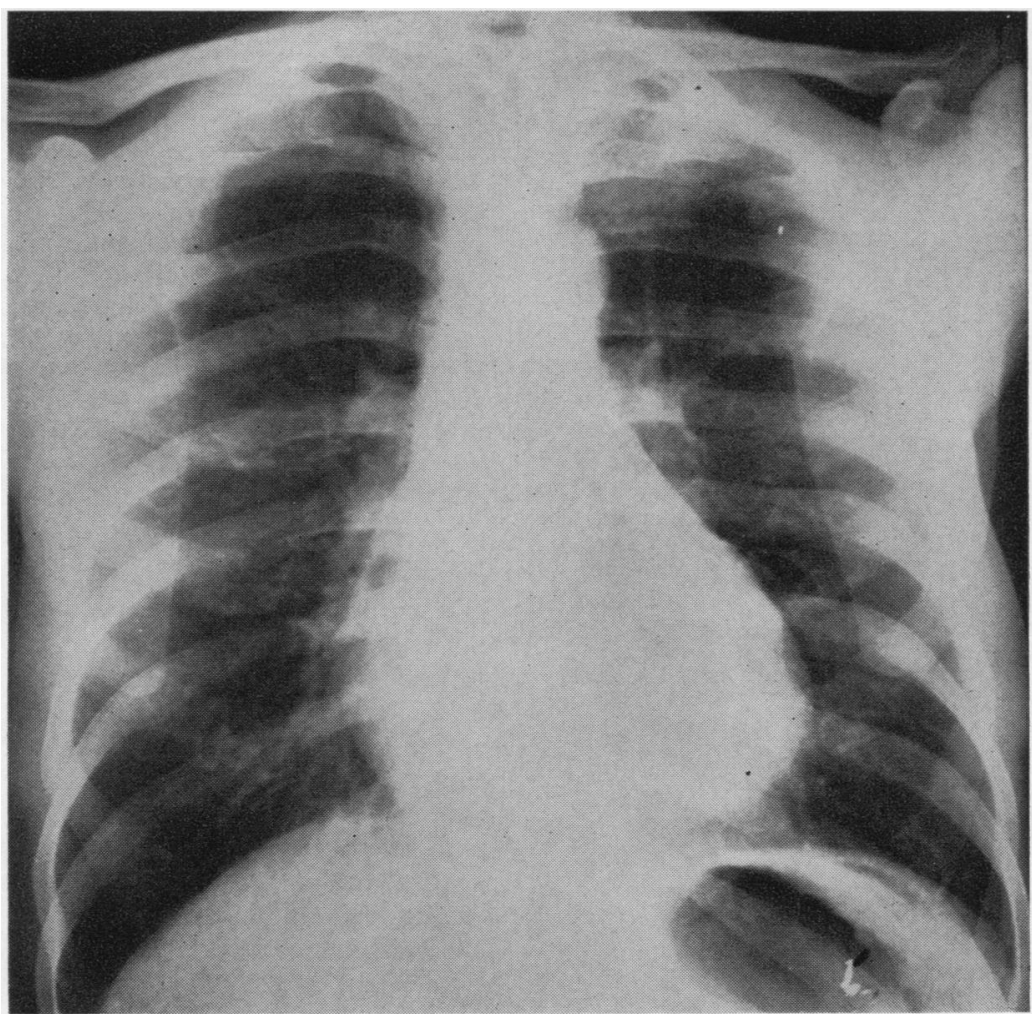

FIG. 13. Case 4. Lordotic view showing left upper zone lesion. 
patient was aware of the outlook following operation, but his pain was so severe that he asked for removal of the tumour to be undertaken.

Although pain has been relieved, resection usually has little effect in prolonging life. The relief of pain may simply be due to allowing the tumour more space to grow, in this way reducing the pressure effects in bone and nerve roots. Seven of the 11 patients operated on have died of paraplegia with retention of urine from involvement of the spinal cord. When the certainty of vertebral body involvement can be ascertained, operation is contraindicated, but this is difficult by present-day radiological techniques. Involvement of a vertebral body may certainly exist without pre-operative radiological evidence of involvement. No attempt has yet been made to include the involved portion of vertebral body in the resection. Residual tumour in the vertebra at the time of operation has presumably been the reason for the incidence of paraplegia in this small series.

CASE 4 A man, aged 65, was referred from the physiotherapy department complaining of pain in the left shoulder and down the left arm. A radiograph of the patient's chest is shown in Figure 12; the apical tumour is more clearly seen in a lordotic view (Fig. 13). Bronchoscopy was negative. On account of the uncertain outcome following surgery and the patient's age, operation was not advised. Various methods were used to control the pain but these were not effective, and five months after the first consultation, at the patient's request, operation was carried out. At operation the tumour of the upper lobe was found

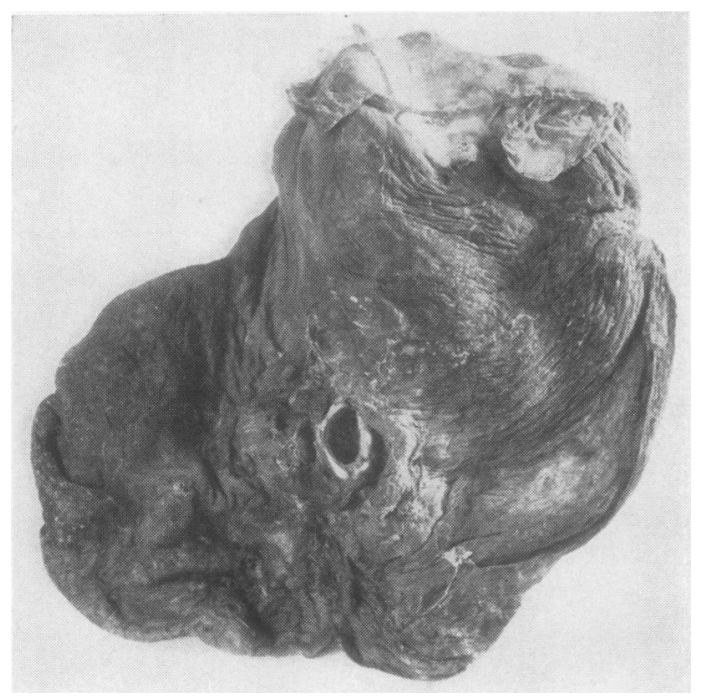

FIG. 14. Case 4. The resected left upper lobe. The peripheral tumour is grooved by the rib. to be fixed to the posterior end of the second left rib; the left upper lobe and the second rib were resected.o The first thoracic root was preserved but the second, 듬 third, and fourth roots were divided. Histological $\overline{\frac{F}{5}}$ examination showed the lesion to be a squamous $\overrightarrow{\mathbb{D}}$ carcinoma of the lung. The specimen is shown in $\varrho$ Figure 14. The patient convalesced normally after this कै operation, but lived in good health, free of pain, for $\vec{\circ}$ four years, except for some recurrence of the arm pain in the last two months of life. He died in hospital $\vec{\omega}$ of acute retention of urine ; necropsy was not carried $\stackrel{\circ}{\circ}$ out.

CASE 5 A man, aged 56, complained of pain down $\vec{\infty}$ the inner side of the right arm to the elbow of tenweeks' duration. A Horner's syndrome was present ${ }_{-}$ on the right side. The chest radiograph is shown in 응 Figure 15. No tumour was visible at bronchoscopy. At operation a tumour was found adherent to the second rib posteriorly: the lesion was probably of pulmonary origin, although the parietal pleura $\frac{\hat{T}}{\partial}$ appeared to be invaginated into the substance of the upper lobe. The second rib, the tumour, and the right $\odot$ upper lobe were removed. The patient convalesced normally and he was immediately relieved of the pain $\square$ in the arm. The report on the tumour, a squamous cell carcinoma, states that, 'except where the growth has obviously broken through into the lung paren-음 chyma, it is more or less limited on its deeper aspect by a collagenous and fibrous capsule alongside which $\varnothing$ lie foci of lymphoid tissues. Although there are no $\overrightarrow{\overrightarrow{0}}$ diagnostic features, this capsule is remarkably like an $\frac{0}{3}$ invaginated pleura.' The evidence that this lesion was other than a peripheral lung carcinoma was incon $-\frac{\overrightarrow{0}}{0}$ clusive and a presumptive diagnosis of lung carcinoma was reached. The specimen is shown in Figure 16. Within three months of operation radiological evidence of erosion of the posterior ends of the first and third $x$ right ribs appeared, although the patient remained $\frac{}{5}$ free of pain. He died without any recurrence of the arm pain five months after operation, from retention $ᄋ$ of urine and with total paralysis of both legs from spinal cord involvement. Necropsy was not carried 0 out.

\section{OESOPHAGO-BRONCHIAL FISTULA}

Penetration of the oesophagus by lung carcinoma $N$ is a complication which adds considerably to the patient's distress. When this is a terminal event, $\square$ judged by the patient's condition and other evidence of spread of the tumour outside the lung, active surgical measures have no place in pallia- $\stackrel{\infty}{\sim}$ tion. Exceptionally a fistula may occur between 0 the air passages and the oesophagus in a patient ${ }^{\circ}$ without other evidence of lung tumour and whose $\stackrel{\mathbb{D}}{\mathbb{D}}$ general condition remains unaffected for some $\frac{\mathscr{D}}{\mathbb{D}}$ weeks. The difficulties in the management of such $\cong$ a condition may be illustrated by a brief description of a patient who first stimulated an interesto 


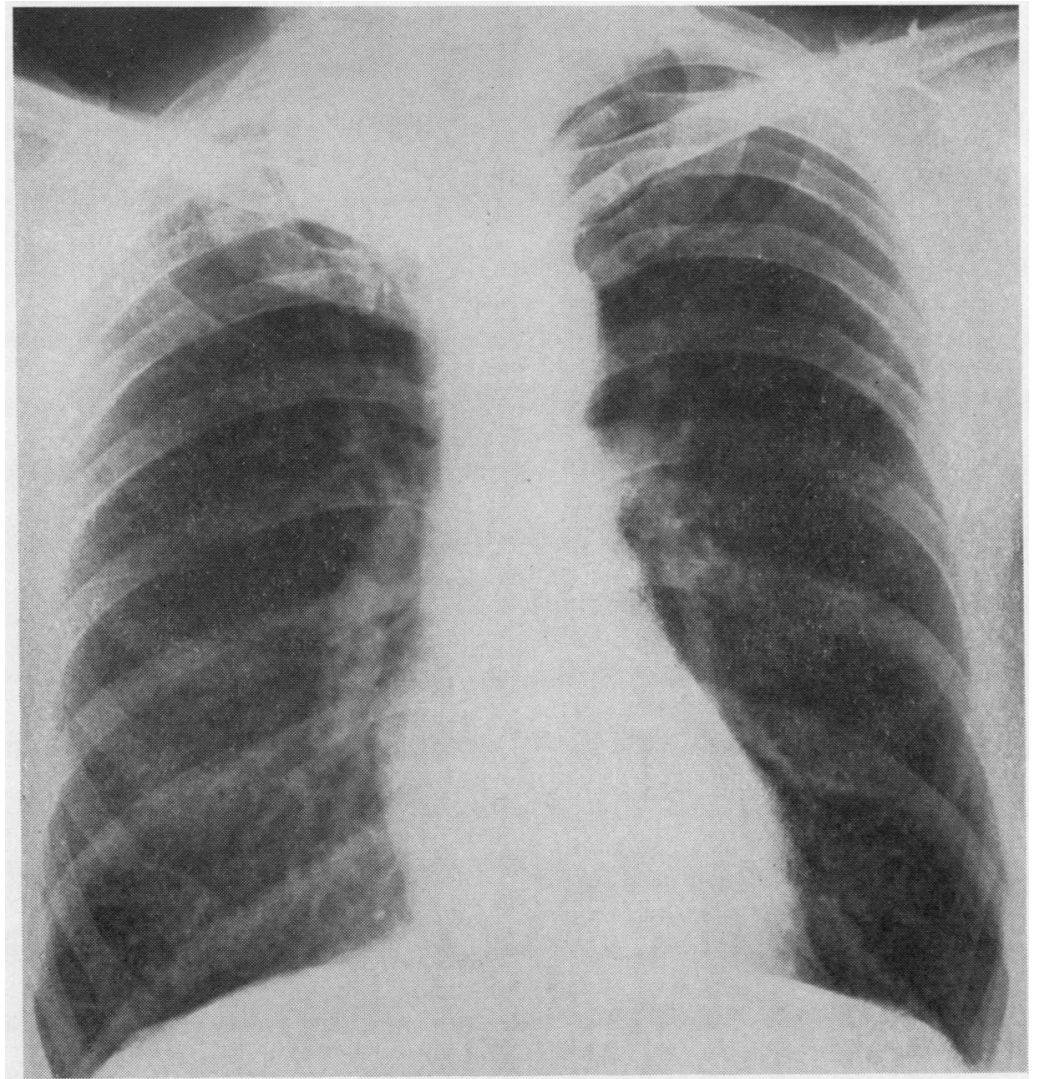

FIG. 15. Case 5. Chest radiograph showing right upper lobe tumour.

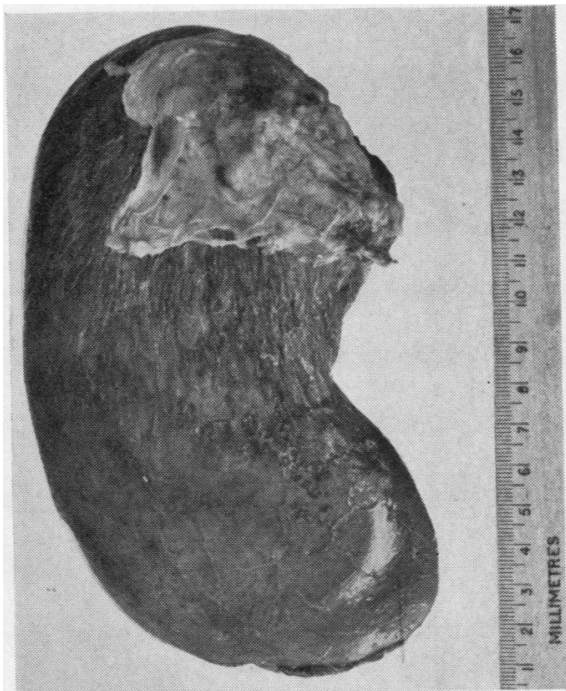

FIG. 16. Case 5. The resected right upper lobe with adjacent parietal pleura. The tumour is presumably of pulmonary origin.

in the possibility of removal of the lung and oesophagus as a means of treating this complication.

This patient, at the age of 39 , had a left lower lobectomy for a squamous-celled carcinoma in 1954. He remained well at his previous occupation for over four years, at which time he noticed an irritating cough each time he swallowed fluids. A lipiodol swallow confirmed the presence of a communication between the oesophagus and the bronchus, in the region of the left lower lobe stump. Squamous carcinoma was obtained from the oesophagus by biopsy at $29 \mathrm{~cm}$. and from the bronchial suture line. From consideration of conventional methods of treating such a complication, resection of the oesophagus with the remaining upper lobe was not attempted and the patient's condition was allowed to deteriorate over a period of many weeks. Various methods of treatment, none of which offered hope of cure, were tried. Periods of feeding by parenteral methods, restriction of oral fluids, posturing the patient, feeding by a gastric tube in the stomach, and a prolonged course of chemotherapy, maintained the 
patient's condition for many weeks. In retrospect it was felt that, where the evidence pointed so clearly to a slow-growing locally malignant tumour, a further attempt at a radical cure of the original lesion should have been made, and that if such a relatively favourable combination of circumstances arose in a patient at a future date, removal of the oesophagus, the fistula, and the lung should be attempted. This type of operation has been carried out in two patients from a total of 29 seen with established fistulae ; these two patients will be described. Any other form of less radical surgery appears to have no place in management, but each patient is an individual problem.

It is not known how long an interval of time may elapse between being able to obtain a biopsy of malignant tissue from both the oesophagus and the bronchus and the development of an actual fistula. By producing necrosis of the tumour, cytotoxic drugs may precipitate a large communication between the passages in a patient with tumour tissue in both organs, and we have seen this develop in more than one patient. The choice appears to lie between a firm decision that surgery has nothing to offer or an attempt at a radical removal. The fact that only two out of 29 patients have been operated upon is an indication of the many reasons for adopting the former of these alternatives.

CASE 6 A man, aged 41, complained of haemoptysis during the previous month. Three years previously a chest radiograph had been normal. At the time of examination the chest radiograph showed a large left pleural effusion. Bronchoscopy revealed a left lower lobe carcinoma, confirmed as squamous-celled. Aspiration of the left pleural cavity produced a heavily bloodstained effusion on two occasions containing malignant cells. Because of the nature of the effusion the patient was referred for radiation therapy; within three months of treatment the chest radiograph showed no trace of the original lesion and the patient felt better. However, he soon began to complain of dysphagia and the actual coughing up of particles of food with paroxysms of coughing when taking fluids. A lipiodol swallow confirmed a communication between the oesophagus and the left main bronchus. A biopsy of squamous cell carcinoma was obtained from the left lower lobe and the oesophagus at $30 \mathrm{~cm}$. The patient's general health was so good that it was felt that a gastrostomy was not in the circumstances justifiable. An operation consisting of removal of the left lung and the oesophagus with exteriorization of the upper oesophagus in the neck and a gastrostomy was proposed. The patient readily agreed. Doubts about the ultimate prognosis and the tissue changes consequent upon the radiotherapy were the two predominant reasons for not contemplating a primary anastomosis of the oesophagus to the stomach at the time of resection.
At operation the oesophagus was freed and divided above the aortic arch, the adventitia of the aorta was dissected, the main bronchus divided at the carina, and the pericardium widely opened. The site of the fistula lay immediately posterior to the pulmonary veins, which were clamped and sutured on the atrium. In freeing the oesophagus, the right pleural cavity was opened. The whole of the pleura was immediately closed with the lung inflated. The oesophagus, as far as the cardia, and the left lung were removed. The lower end of the oesophagus was doubly invaginated. The upper end of the oesophagus was brought out in the neck on the left side and a gastrostomy was performed. The patient convalesced normally from $\vec{\infty}$ this operation and the flow of saliva from the external $\rightarrow$ oesophageal fistula ceased to be troublesome in quantity after the first three weeks. It was decided $O$ to delay any attempt to restore continuity for at least one year from the time of operation. The patient found no difficulty in maintaining nutrition through the gastrostomy. Twelve months later he died from a recurrence of the squamous cell tumour in the trachea. Necropsy showed no spread of the disease outside the thorax. A low-grade infection of the pneumonectomy space was present.

CASE 7 A 51-year-old woman had been treated for achalasia of the cardia for $\mathbf{3 0}$ years. For six months she complained of pain in the back between the shoulder blades. There was no increase in the $\mathbb{D}$ dysphagia. A radiograph of the chest showed some infiltration in the right lower zone and the barium swallow is shown in Fig. 17. At bronchoscopy a tumour was seen blocking the right lower lobe bronchus and at oesophagoscopy a tumour was seen growing from the right lateral wall of the oesophagus at $27 \mathrm{~cm}$. Biopsy from both these tumours showed a squamous cell carcinoma. No actual fistula between $\underset{x}{ }$ the two passages could be seen and it was not possible $\delta$ to be certain of the site of the primary. The patient's general condition was excellent. The radiological extent of the tumour was small, and no metastases could be detected. The tumour was judged to be resectable and the choice lay between a radical removal or treatment by symptomatic measures as $\frac{D}{2}$ symptoms increased. The extent of the tumour in the bronchus precluded the possibility of a lobectomy. $N$ Removal of the right lung, the fistula, and the oesophagus with primary anastomosis of the stomach to the upper oesophagus was decided upon.

Through a laparotomy incision the absence of metastases below the diaphragm was confirmed; the stomach was mobilized and a pyloroplasty carried out. The patient was then placed in the prone position $\mathscr{\mathscr { D }}$ and the right pleura was opened through the bed of ? the resected sixth rib; the posterior end of the fifth rib was also resected. The carcinoma was of small dimensions and appeared to originate in the right lower lobe bronchus and to be growing into the lateral wall of the oesophagus. It was spherical and about $3.5 \mathrm{~cm}$. in diameter. No glands were involved. The position of the tumour in the bronchus and the 


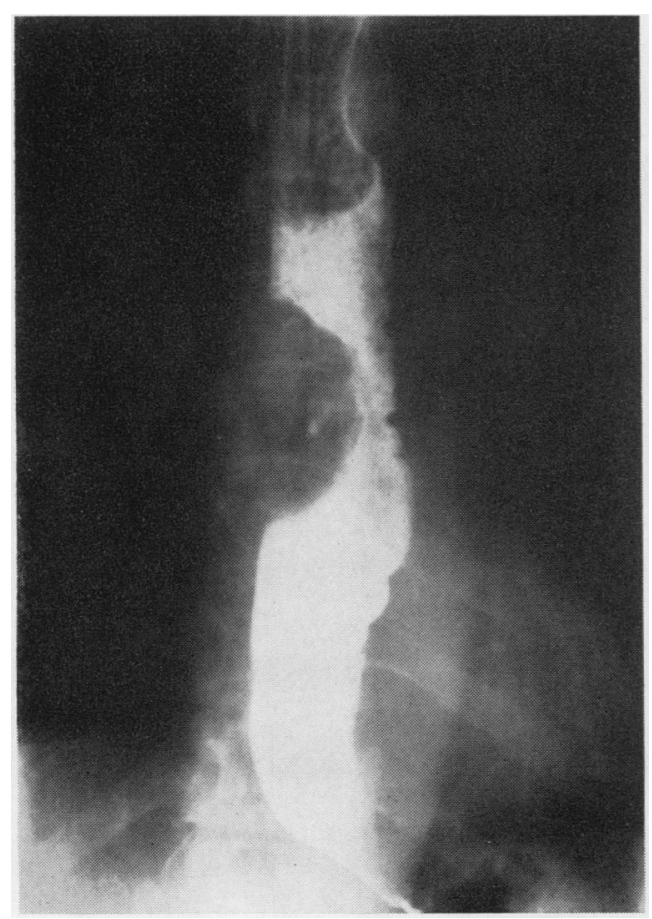

Fig. 17

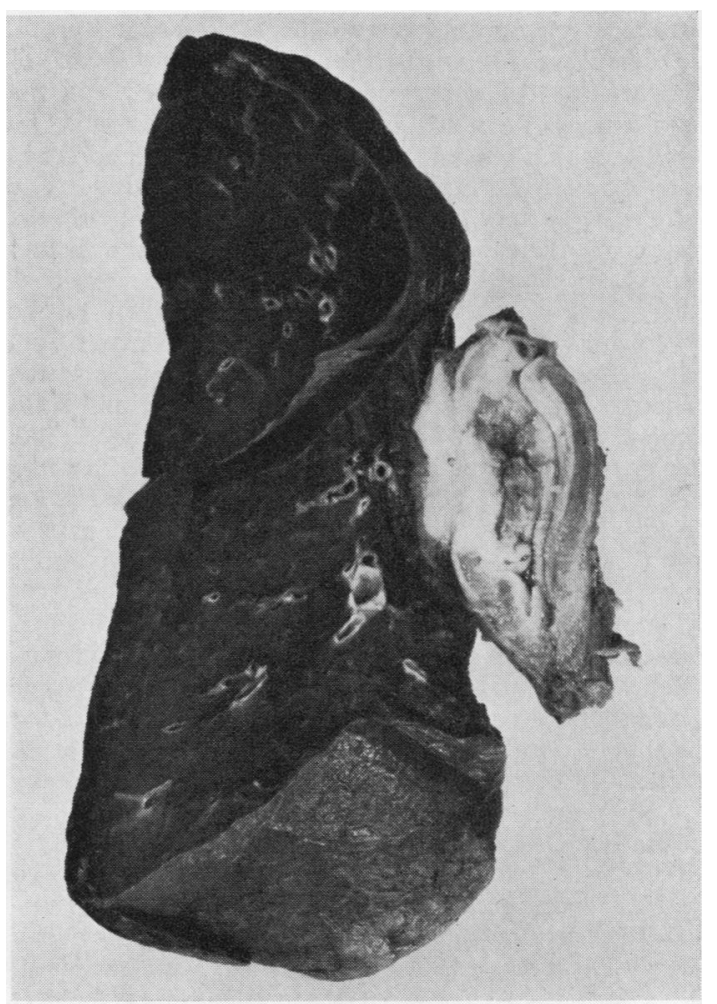

Fio. 19

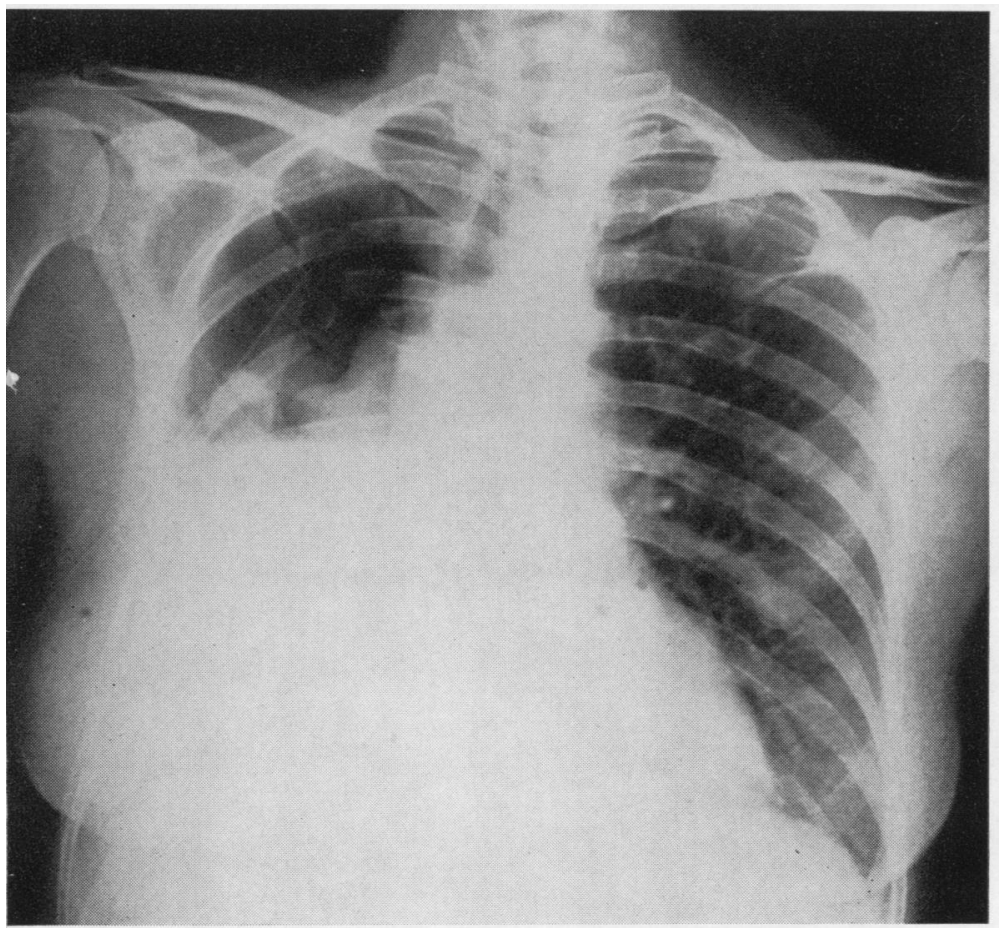

FIG. 17. Case 7. The indentation caused by the right lower lobe lung tumour. No fistula is detectable in this barium swallow examination.

FIG. 18. Case 7. The chest radiograph on the tenth post-operative day. A small intragastric fluid level is seen in the stomach at the site of anastomosis at the level of the resected fifth right rib. The pneumonectomy space contains clot and a little blood.

FIG. 19. Case 7. The resected right lung and oesophagus. The lung has bcen sectioned posterior to the plane of the endobronchial portion of tumour. 
extent of the fusion between the main bronchus and the oesophagus prevented any satisfactory form of local excision. The azygos vein was divided and the main bronchus divided and sutured at the carina. The oesophagus was transected at azygos level and freed from the inner aspect of the aortic arch. The pulmonary artery and the common origin of the pulmonary veins on the atrium were clamped and sutured from within the pericardium. The mobilization of the oesophagus was continued down to the cardia and the previously mobilized stomach was delivered into the chest cavity. The oesophagus was transected at the cardia and the oesophagus and right lung were removed. The fistula was not opened. The cardia was invaginated, the stomach sutured to the vertebral bodies, and an anastomosis of the fundus of the stomach to the oesophagus above the azygos arch was completed. The chest wall was closed without drainage.

The patient's early convalescence followed a normal course apart from persistent pain in the left iliac fossa, which was thought to be due to a partial volvulus of the sigmoid colon. The abdomen was not distended and by the fifth day the bowels had been opened. A chest radiograph on the tenth post-operative day (Fig. 18) and the resected specimen (Fig. 19) are shown.

The pneumonectomy space was aspirated as a routine procedure on the first, third, and fifth postoperative days. On the fourteenth post-operative day the patient vomited, the abdominal pain increased, and a definite tender mass was palpable in the left iliac fossa. The signs were those of a volvulus of the sigmoid colon. A further laparotomy was performed and a perforated volvulus of the colon found. The extent of the local changes made an accurate diagnosis of the lesion impossible and nothing could be done except to drain the abscess and exteriorize the gangrenous portion of the sigmoid colon. The exact origin of this presumed volvulus was not detectable. The patient died 48 hours after this second operation: terminally a leak in the oesophageal suture line occurred.

\section{SUMMARY}

The results of resection of lung carcinoma, in which tumour removal was not complete, are presented. The results are not intended to support a policy of bringing more patients within the scope of surgery. Resection of this type is a satisfactory method when treatment has reached the stage of exploration of the lesion and total removal is not possible. Operations for superior vena caval obstruction, the superior sulcus syndrome, and oesophago-bronchial fistula due to lung carcinoma are described.

I am indebted to Dr. J. C. A. Raison, Dr. D. R. Rigg, and Dr. J. D. H. Wearing, who were concerned $\vec{\infty}$ with the welfare of all these patients. Radiotherapy was carried out by Dr. K. Sicher and Dr. T. W. i Backhouse, of the Radiotherapy Department at the Coventry and Warwickshire Hospital. Dr. A. P. Prior, of the Central Pathological Laboratory, Warwick, reported on the pathology of the tumours, and $\mathrm{Mr}$. T. L. Skuse and Mr. L. Hine prepared and photographed the specimens. Miss D. Beauchamp supervised the follow-up.

\section{REFERENCES}

Ashburn,[F. S., Sewell, W.' H., and Huggins, C. E. (1956). J. thorac. Surg., 31, 618.

Botham,' R. J., Dracopoulos, T. T., and Gale, J. W. (1960). Ibid., 39, 202.

Chamberlain, J.'M., McNeill, T. M., Parnassa, P., and Edsall, J. R. (1959). Ibid., 38, 727.

Chardack, \}W.!M.,'and MacCallum, J. D. (1953). Ibid., 25, 402.

- (1956). Ibid., 31, 535.

Clarke, B. E. (1934). Amer. J. Path., 10, 693.

Fried,'B. M. (1948). Bronchiogenic Carcinoma and Adenoma, p. 181 Williams and Wilkins, Baltimore.

Herbut, P. A., and Watson, J.IS. (1946). Arch. Path. (Chicago), 42, 88.

Holman, C. W., and Steinberg, I. (1954). J. Amer. med. Ass., 155, 1403.

James, I., and Pagel, W. (1944). Brit. J. Surg., 32, 85.

Jarvis, F. J., and Kanar, E. A. (1954). J. thorac. Surg., 27, 213.

Morris, J. H., and Harken, D. E. (1940). Ann. Surg., 112, 1.

Pancoast, H. K. (1924). J. Amer. med. Ass., 83, 1407.

_ (1932). Ibid., 99, 1391.

Scannell, J. G., and Shaw, R. S. (1954). J. thorac. Surg., 28, 163.

Smith, R. Abbey (1957). Thorax,12, 79.

Thomas, C. Price (1959). Ann. roy. Coll. Surg. Engl., 24, 345. 